\title{
The Perpetrators of Workplace Bullying in Schools: A South African Study
}

\author{
Corene De Wet \\ School of Open Learning, University of the Free State, Bloemfontein, South Africa \\ Email: dewetnc@ufs.ac.za \\ Lynette Jacobs \\ Faculty of Education, University of the Free State, Bloemfontein, South Africa \\ Email: jacobsl@ufs.ac.za
}

\section{Doi:10.5901/mjss.2014.v5n16p567}

\begin{abstract}
This study investigates workplace bullying (WPB) in schools. A voluntary sample of 999 teachers completed the self-reporting questionnaire. Only 32 of the participants acknowledged that they bullied their colleagues. Statistics and content analysis were used to identify and characterise the bullies. An analysis the self-identified bullies' qualitative responses to an open-ended item reveal that bullies verbally, emotionally and physically abuse their colleagues. The findings indicate that bullies rationalise their negative behaviour. This study highlights the interplay between personal, organisational and societal factors as an explanation for WPB. It is concluded that WPB needs to be addressed on policy and institutional levels.
\end{abstract}

Keywords: mobbing self-identified bullies, South Africa, teachers, workplace bullying,

\section{Introduction}

Since the ground-breaking study by Leymann (1996), workplace bullying (WPB) has begun to receive more attention and recognition as an important social and organisational problem (Moreno-Jiménez, Muňoz, Salin \& Benadero, 2008). Research has established that WPB is a fairly common phenomenon (Agervold, 2007; Parzefall \& Salin, 2010; Samnani \& Singh, 2012) that can result in complications for employees, including anxiety, depression, post-traumatic stress and suicide (Braithwaite, Ahmed \& Braithwaite, 2008; Leymann, 1996). WPB not only affects the mental and physical health of the victims, but has cost-implications for the organisation, such as complaints resulting in lawsuits, absenteeism, staff conflict, impaired job performance and high staff turnover (Braithwaite et al., 2008; Moreno-Jiménez et al., 2008).

WPB involves persistent, offensive, abusive and/or intimidating behaviour that makes the target feel threatened, humiliated, isolated, stressed and/or unsafe at work (Branch, 2008; Branch, Ramsay \& Barker, 2013; Hauge, Skogstad \& Einarsen, 2007). A power imbalance between the victim and the perpetrator is regarded as a core characteristic of bullying (Branch, 2008; Samnani \& Singh, 2012). This power can take a number of forms (e.g. physical) and is not limited to hierarchical power (Samnani \& Singh, 2012). An important difference between 'normal' conflict and bullying is not what and how it is done, but the frequency and longevity of what is done (Agervold, 2007; Branch, 2008; Leymann, 1996). Bullying is not an either-or phenomenon, but a gradually evolving process (Einarsen, 1999).

A wide variety of negative acts that may constitute WPB have been identified by researchers (cf. Agervold, 2007; Cunniff \& Mostert, 2012; Einarsen, 1999). WPB surveys typically include 22 to 45 items on different negative acts (Agervold, 2007). The questionnaire used in this study included 43 negative acts. These acts are often categorised. Zapf (1999) categorised five types of WPB: work related bullying which may include changing the victim's work tasks or making them difficult to perform; social isolation; personal attacks or attacks on the victim's private life by ridicule, insulting remarks, gossip or the like; verbal threats where the victim is criticised, yelled at or humiliated in public; and physical violence or threats of such violence.

In an attempt to explain WPB and to look for ways to address this problem, researchers have examined the personality traits of victims (Shallcross, Sheehan \& Ramsay, 2008; Zapf, 1999) and perpetrators (Braithwaite et al., 2008; Glasø, Nielsen \& Einarsen, 2009), along with the work environment (De Wet, 2010; Zapf, 1999). Research findings on the victims of WPB frequently emanate from self-reporting surveys or qualitative studies (Jenkins, Zapf, Winefield \& Sarris, 2012; Shallcross et al., 2008). Findings on perpetrator behaviour and personality traits have generally been reported from 
the perspective of the victims. The perspectives of perpetrators of WPB are usually not sought (e.g. Baillien, Neyens, De Witte \& De Cuyper, 2008; Einarsen, Hoel, Zapf \& Cooper, 2011; Hauge, Skogstad \& Einarsen, 2009; Van den Broeck, Baillien \& De Witte, 2011). According to Samnani and Singh (2012:582) WPB research "investigating the perpetrator represents a current challenge in the literature". Key findings from the few studies that have investigated the perpetrators - from the perspectives of the victims as well as self-identified or alleged perpetrators - will be presented in Section 3.

While WPB has received a great deal of attention in Western Europe, the United Kingdom, Canada, the USA and Australia (Blasé, Blasé \& Du, 2008; Moreno-Jiménez et al., 2008; Parzefall \& Salin, 2010), it is barely being studied in South Africa (Cunniff \& Mostert, 2012). With the exception of Cunniff and Mostert's (2012) large-scale study ( $n=13$ 911) and Marais-Steinmann's (2003) Internet survey ( $n=1$ 018), South African studies have been either limited surveys (e.g. Momberg, 2011) or qualitative studies (e.g. De Wet, 2010; Kirsten, Viljoen \& Rossouw, 2005). Only a few researchers (De Wet, 2010; Kirsten et al., 2005) have shed some light on the perpetrators of WPB within the South African context, yet none of them has attempted to obtain the input of the bullies. Notwithstanding this scarcity on research on WPB in South Africa, two survey studies have shown that WPB is a serious problem. Marais-Steinmann (2003) found that $77.8 \%$ of South Africans feel bullied in the workplace, while results from Cunniff and Mostert's (2012) study showed that 31.1\% of the participants had experienced WPB.

The preceding exposition shows that despite the growing body of research on WPB worldwide, there is a need for research on the topic within the South African context, as well as empirical research that focuses on the perpetrators of WPB. Rayner and Cooper (2003, in Matthiesen \& Einarsen, 2007:736) refer to the latter as a 'black hole' in WPB research worldwide. The present study aims to address these gaps within the South African and international contexts by focusing on the perpetrators of WPB in South African schools. The following three research questions will guide this study:

- Who are the perpetrators of WPB in schools?

- How do self-identified staffroom bullies abuse their colleagues?

- Why are teachers committing WPB?

Although some data will be drawn from victims' and bystanders' responses to survey items, the study will primarily utilise data emanating from self-identified bullies' responses to an open-ended request in a survey on WPB in schools.

\section{Theoretical Framework}

Theoretical development in the WPB literature has been described as weak (Blasé \& Blasé, 2002; Parzefall \& Salin, 2010; Samnani, 2013). Researchers have however, drawn on a variety of theoretical frameworks, such as the social exchange theory (Parzefall \& Salin, 2010), a work environment framework (Hauge et al., 2007), Bronfenbrenner's ecological systems theory (De Wet, 2010), critical management theory (Samnani, 2013), social dominance theory (SDT) (Parkin, Fishbein \& Richey, 2006), job demands-resources model (Van den Broeck et al., 2011) and symbolic interactionism (Blasé \& Blasé, 2002; Samnani, 2013) to frame and understand bullying behaviour. In this study we draw upon one of the most widely known and comprehensive frameworks of WPB proposed by Einarsen et al. (2011), and SDT (Pratto \& Stewart, 2012) to study the perpetrators of WPB in schools.

Einarsen et al. (2011) see WPB as a complex social phenomenon characterised by multi-causality, involving a range of factors found at cultural and socioeconomic, organisational, social group and individual levels that may inhibit or contribute to WPB. On an individual level, the personalities of both the victim and the perpetrator may be causes of both the bullying behaviour and the perception of being bullied. On a social-group level bullying may be explained in terms of scapegoating processes in groups and organisations: groups displace their frustration on a less powerful group member. On an organisational level a culture of intolerance, retribution and competitiveness perpetuates bullying. This model also focuses on the societal level, consisting of national, cultural, legal and socioeconomic factors that may contribute to WPB. Although this study focuses on the individual level and the interaction between the bullies and their victims - as seen through the eyes of the bullies - we may not ignore the other levels. Bullying behaviour may, for example, be seen as the personification of the narcissistic personality of the bully, "but they will act as bullies only when the organisational culture permits or even rewards this kind of misbehaviour" (Einarsen et al., 2011:31).

SDT is a multi-level theory that suggests that all societies construct group-based hierarchical systems based on important characteristics, such as ethnicity, class or religion and that some members of society are motivated to achieve membership in higher status (or dominating) groups and legitimise dominance over perceived inferior groups (Pratto \& Stewart, 2012; Shao, Resick \& Hargis, 2011). Social Dominance Orientation (SDO) reflects an ideology of legitimised societal inequality and the degree to which individuals' desire and support group-based hierarchy and the domination of 'inferior groups' by 'superior groups' (Shao et al. 2011). Individuals with high levels of SDO desire power and status, 
pursue self-interest over group interest, and seek to hold dominance over others. SDO is also associated with interpersonal dominance, prejudice and a lack of empathy for others. To gain a competitive advantage over others, individuals with a high SDO may, for example, intentionally harm colleagues by spreading rumours or publicly humiliating those they perceive to be inferior (Shao et al., 2011). SDT thus explains the negative behaviours of the bullying colleague as systematic, intentionally disempowering acts to perpetuate the dominance of the superior group/individual over the inferior group/individual.

\section{The Perpetrators of WPB: A Review of the Literature}

Research focusing on the perpetrators of WPB is scarce. In their quest to investigate perpetrators of WPB researchers mostly use data originating from interviews and/or the narratives of victims of WPB or utilise data from survey items alluding to the character, gender and position of the bully. The review will firstly focus on existing literature studies on the perpetrators of WPB; thereafter, findings emanating from data supplied by victims of WPB and other employees who indicated that they were not victims of bullying will be presented. The review will lastly present findings from a few empirical studies that utilised data provided by self-identified bullies, as well as alleged bullies.

Researchers often turn to existing literature rather than reporting on findings from their own empirical studies to characterise perpetrators of WPB. Summarising the findings from previous research, Zapf and Einarsen (2003) identified three antecedents of bullying related to perpetrator characteristics: self-regulatory processes related to threatened selfesteem; lack of social competencies; and bullying as a result of internal rivalry or competition in the workplace, especially when there is a lack of formal structures and clearly designated work tasks and responsibilities. Based on an extensive literature review Glasø et al. (2009) additionally identified the following characteristics of bullies in the workplace: dominant, defensive, anxious and aggressive; they might also be either assertive or unassertive and they seem to lack social competence. Hauge et al. (2009) moreover note that previous research proposes that bullying is often a coping mechanism for employees to defend themselves against further mistreatment. Using the existing literature, Braithwaite et al. (2008) identify impulsivity, emotional reactivity, cynicism, low tolerance for ambiguity and aggressiveness as qualities that predispose people to bullying others.

Research findings on the perpetrators of WPB tend to originate from surveys or qualitative data obtained from victims and/or bystanders. Victims of WPB who took part in Lutgen-Sandvik and McDermott's (2011:342) study believe that there was "something very wrong" with the bullies. Participants made mention of their bullies' unpredictable work oversight, inconsistent emotional displays and highly changeable mood swings. Victims furthermore labelled their bullies as mentally ill, evil, deceitful, envious and power-hungry individuals. Participants also believed that their colleagues bullied them in order to take their personal frustrations out on others or to shift the blame for their mistakes or lack of skills (Lutgen-Sandvik \& McDermott, 2011). Furthermore, a study by Baillien et al. (2008) found that bullies tend to be intolerant and very strict. Baltaş $(2003$, cited by Cemaloglu, 2007) portrays perpetrators of WPB negatively as people who try to compensate for their weaknesses, fears and low self-confidence by humiliating others. They are also intolerant of differences, hypocritical, attempt to establish superiority over others, over controlling and jealous. Teachers who took part in Blasé et al.'s (2008) study likewise portrayed their bullies as jealous and incompetent leaders who trample on those who question their actions and policies. In a qualitative study by Blasé and Blasé (2002) victims of WPB depicted their bullying principals extremely negatively, as among other things thieves, liars and autocrats. Teachers who took part in De Wet's (2010:1453) qualitative study also described their bullies negatively as destructive, narcissistic, manipulative, envious, evil and hypocritical. Her data however, also showed that bullies were talented, articulate and systematic individuals who know how to play "the power game".

Existing evidence shows that perpetrators of WPB are more often male than female (Hauge et al., 2009; Samnani \& Singh, 2012). Supervisors have been shown to be the most frequent perpetrators of WPB (Cunniff \& Mostert, 2012; Lutgen-Sandvik \& McDermott, 2011). Research by Branch (2008), Branch et al. (2013) and Jenkins et al. (2012) however suggests that upward bullying, that is bullying of managers by their subordinates, is not an uncommon occurrence. Despite their position of authority, managers who are victimised feel powerless to address their bullying staff members' inappropriate behaviour. Formal structures of authority may thus be nullified by bullying.

Within the South African context inadequate attention has been given to perpetrators of WPB: using a vignette of a school principal and a diagnostic criterion for Narcissistic Personality Disorder (NPD), as point of departure, Kirsten et al. (2005) typify the bullying principal as someone suffering from NPD. De Wet (2010) uses data obtained from victims of supervisor abuse to characterise bullying principals.

Whilst we were unable to find any South African study that uses data obtained from perpetrators or alleged perpetrators of WPB to gain insight into WPB, we identified eight recent, relevant international studies that shed light on 
WPB from the perspective of self-identified and/or alleged bullies.

Jenkins et al. (2012:489) claim that research that focuses only on WPB from the perspective of the victims may not provide a holistic depiction of the phenomenon. They subsequently interviewed 24 managers/supervisors who had been accused of WPB during the two years preceding their study. Most of the participants denied the bullying allegations and described their behaviour as "reasonable, although unpopular, aspects of their role". All the participants reported that they had carried out "some kind of negative workplace behaviours against others". From the alleged bullies' perspective the negative behaviour was reasonable within the context of the situation and was therefore seen as not bullying. From the data provided by the alleged bullies, Jenkins et al. (2012) identified a highly stressful workplace, including ambiguous roles, staff shortages and high levels of conflict, as well as inappropriate social behaviours carried out by others, as reasons for the participants' negative behaviour. These findings are supported by Bloch (2012). In his study, selfidentified bullies classified their victims as violators of basic norms of the work community. These perceived violations triggered moral emotions such as contempt, anger, vengeance and disgust. These emotions were consequently converted into negative actions.

In a study that focused on the different role-players in WPB, namely victims, non-victims and bullies, Glasø et al. (2009) found that self-reported perpetrators were more domineering, vindictive, cold, socially avoidant, intrusive and distrustful than non-victims. The researchers furthermore found that perpetrators are less exploitable than victims. They note that bullies may not be aware of how their behaviour affects the victims (Glasø et al., 2009). The self-reported perpetrators who took part in Matthiesen and Einarsen's (2007) study report more aggressiveness than the victim group. They admit stronger aggressive reactions after provocations in the workplace. In another study it was found that perpetrators were socially dominant and low in social desirability (Parkin et al., 2006). Parkin et al. (2006:2571) moreover, found that perpetrators have a low ability to assume the perspective of another person. They consequently lack "an empathic inhibitor of aggressive behaviour". A study by Van den Broeck et al. (2011) showed that conflict in the workplace may escalate due to job demands and the availability of job resources. From the perspective of the bullies, De Cuyper, Baillien and De Witte's (2009) study additionally found that the relationship between WPB and job security was stronger when perpetrators were highly employable, suggesting that perpetrators are more likely to bully if they are able to get another position more easily. Van den Broeck et al. (2011) argue that powerful employees, who have access to job resources, may become bullies. Hauge et al. (2009) found that individuals who are exposed to bullying have a significant predisposition to engage as perpetrators of WPB.

Findings from the literature reviews, as well as empirical studies involving victims, non-victims, self-reported and alleged bullies are in agreement that explanations for bullying should be sought within individuals, workplaces and at societal levels. This links with Einarsen et al.'s (2011) framework, and SDT. The theory that highly employable, powerful and capable perpetrators engage in bullying behaviour to gain dominance over incompetent, inferior and powerless colleagues is especially noticeable in studies that purposefully sought the participation of bullies.

\section{Research Methodology}

\subsection{Research approach}

In this study we followed a dual-paradigmatic approach, namely functionalism and interpretivism to investigate the perpetrators of WPB. Functionalism represents the dominant paradigm in WPB research. WPB research using a functionalist lens seeks to explain WPB through the discovery of regularities and causal relationships that exist between variables of interest. The interpretivism approach, on the other hand, will provide a rich description focusing on the experiences of the perpetrators and their understanding of negative behaviour (Samnani, 2013). Whilst the latter will provide a voice to the perpetrators of bullying, the functionalist lens will shed light on the ordinariness of WPB in schools.

\subsection{Research instrument}

A five-section questionnaire prepared after an extensive literary review and scrutiny of existing WPB questionnaires was used for data collection. In the first section the participants' demographic information was requested. In the second section questions were asked about their exposure to predetermined acts of WPB; in the third section information was asked about the professional identity of the perpetrators; the fourth addressed the impact of the bullying experience on the participants; and the last section contained four open-ended questions/requests. This article will focus on the participants' responses to the third section of the questionnaire, as well as the following open-ended request: "If you have ever bullied one or more of your colleagues, please feel free to share your experiences with us". 
Existing WPB literature and questionnaires (cf. Cemaloğlu, 2007; Einarsen, 1999; Yildirim, Yildirim \& Timucin, 2007) informed our decision on which behaviours to include in our research instrument. In this study, we based our questionnaire on a comprehensive literature review on WPB and the existing WPB questionnaires (thus enhancing content validity). The various items related directly to specific constructs that we wanted to measure (working towards construct validity). Before distributing the questionnaires, we gave the instrument to five critical readers for comment, and based on their comments, we improved the face validity of the questionnaire. However, as this is a self-constructed questionnaire that has been used for the first time, there were deficits and we intend to adapt the instrument for usage in future studies.

\subsection{Sample}

A convenient, voluntary sample of teachers who were upgrading their qualifications at the School of Open Learning (SOL), University of the Free State (UFS), South Africa, was opportunistically selected. All the teachers who were invited to take part in the study already have a basic education qualification and are employed in some education-related post.

As this is an exploratory study, we do not claim any inferences, but merely seek to provide some understanding about a phenomenon which has received scant attention from researchers, namely WPB in South African schools. Tutors, who facilitate the contact sessions at SOL, provided each of the students enrolled for an education qualification, with a questionnaire. The students had the choice of completing the questionnaire or destroying it. Those who completed the questionnaire were requested, at their convenience, to return it sealed, to the coordinator of the centre where they attended classes. No record was kept of who returned the completed questionnaire, and this was made clear to the possible participants at the outset. Of the 2742 questionnaires, 1103 were received back (a return rate of $40.2 \%$ ), of which 999 (36.4\%) could be used. The returned questionnaires that were not used were questionnaires on which more than half of the items were not completed.

A mere 3.2\% of teachers who took part in this study conceded, in response to an open-ended request ("If you have ever bullied one or more of your colleagues, please feel free to share your experiences with us"), that they had committed acts of WPB. Table 1 gives a summary of the demographics of the sample, as well as the 32 participants who acknowledged that they were guilty of acts of bullying.

Table 1. Demographic details of the sample and self-identified perpetrators of WPB

\begin{tabular}{|l|c|c|}
\hline & Sample (n=999) & Self-identified bullies (n=32) \\
\hline \multicolumn{3}{|c|}{ Age of the respondents } \\
\hline Male & $14.5 \%$ & $12.5 \%$ \\
\hline Female & $21.8 \%$ & $87.5 \%$ \\
\hline 30 years or younger & $42.6 \%$ & $31.3 \%$ \\
\hline 31 to 40 years & $25.6 \%$ & $37.5 \%$ \\
\hline 41 to 50 years & $9.4 \%$ & $21.5 \%$ \\
\hline 51 to 60 years & $0.2 \%$ & $9.4 \%$ \\
\hline 61 years and older & $0.3 \%$ & - \\
\hline Non-responsive & Post level \\
\hline \multicolumn{3}{|c|}{ Gender } \\
\hline Teachers (Post level 1) & $91.2 \%$ & - \\
\hline Head of Department & $2.2 \%$ & $96.9 \%$ \\
\hline Deputy principal & $0.8 \%$ & $3.1 \%$ \\
\hline Principal & $2.3 \%$ & - \\
\hline Non-responsive & $3.5 \%$ & - \\
\hline \multicolumn{2}{|c|}{ Geographical distribution (school location) } \\
\hline Urban (e.g. Durban) & $10.6 \%$ & $9.4 \%$ \\
\hline Township (e.g. Makelaketla) & $26.4 \%$ & $59.4 \%$ \\
\hline Rural area & $50.6 \%$ & $25.0 \%$ \\
\hline Farm school & $7.1 \%$ & $6.3 \%$ \\
\hline Informal settlement & $1.6 \%$ & - \\
\hline Non-responsive & $3.7 \%$ & - \\
\hline \multicolumn{2}{|c|}{} & \\
\hline & & - \\
\hline
\end{tabular}




\subsection{Research ethics}

The participants' dignity, privacy and interests were respected at all times. The questionnaires did not contain any identifying aspects, names, addresses or code symbols. Before completing the questionnaires, the participants were informed that the process was completely voluntary and that they could withdraw at any stage during the process. Each participant completed an informed consent form. They received no financial or other reward for taking part in the study. Permission for this study was obtained from the Dean of the SOL. Ethical clearance was also obtained from the Faculty of Education, University of the Free State's Ethical Clearance Committee (UFS-EDU-2013-0013).

\subsection{Capture and analysis of the data}

An experienced typist captured the data from the questionnaires using MS Excel and MS Word and spot checks were made for accuracy. The statistical data were analysed, using the STATA IC11 software. In line with the purpose of this paper, we made use of frequencies to identify the perpetrators of WPB in schools.

Henning, Van Rensburg and Smit's (2011) guidelines for qualitative content analysis were used to reduce, condense and group the content of the participants' answers to the open-ended statement. A coding frame was drawn up, also providing for verbatim reporting where applicable. Both researchers worked though all the data and coded them independently. Related codes were thereafter organised into categories. After we had completed the categorisation, we re-read the participants' answers to the questions to check whether we had captured all the important insights that had emerged from the data. The categories, patterns and themes, which could also be linked to the aim of this article were identified and described. The identification of emergent themes allowed the information to be analysed and related to the literature.

In the subsequent discussion of the qualitative data the following symbols will be used to identify the 32 selfidentified bullies: M (male), F (female), T (Post level 1 teacher) and HoD (Head of Department). The self-identified bullies will also be numerically identified (1-32).

\section{Findings and Discussion}

\subsection{The perpetrators of WPB}

In the search for an answer to the first research question we looked at participants' responses to a closed question ("Who was, for the most part, responsible for most/all of the negative behaviour towards you?"), as well as their answers to the open-ended request.

Only 3.2\% of the teachers who took part in our study conceded - in response to the open-ended question - that they bully their colleagues. Reluctance to concede being guilty of committing WPB is not uncommon in WPB research. Only 42 of 2539 (1.65\%) employees who took part in a Norwegian study answered in the affirmative to a self-labelling item concerning whether or not they were perpetrators of WPB (Glasø et al., 2009). In a study by Matthiesen and Einarsen (2007) $5.4 \%$ of the 2215 participants admitted to being perpetrators of bullying at work. Matthiesen and Einarsen (2007) found that the self-reported bullies underestimate the prevalence of WPB. This may be attributed to bullies' lack of critical self-reflection (Jenkins et al., 2012) or a tendency among participants to give socially acceptable responses (Matthiesen \& Einarsen, 2007).

The majority of the 999 respondents who took part in our study (90.8\%) indicated that they experienced some form of WPB. A relatively large percentage of theses respondents, namely $41.4 \%$ indicated that they were mostly bullied by post level 1 teachers, followed by principals (23.7\%), administrative staff at school (17.0\%), the Head of Department at the school (15.5\%) and the deputy principal (5.2\%). A few participants (2.3\%) indicated that people not listed were responsible for victimising them, namely parents and members of School Governing Bodies. These percentages confirm research that WPB occurs at all levels of an organisation (Branch et al., 2013), but rejects the notion that managers/supervisors are mostly responsible for WPB (Cunniff \& Mostert, 2012; Lutgen-Sandvik \& McDermott, 2011).

The dual-paradigmatic approach allows us to look beyond statistics. Through their responses to the open-ended request, the bullying teachers gave the readers, although inadvertently, an insight into their demeanour. The following exposition will portray the bullying participants as arrogant, self-important individuals who strive to domineer those they perceive as inferior: A female teacher (FT), who admits that she is bullying a colleague who is also studying at the UFS, unsympathetically wrote that this colleague "often feels useless and has low self-esteem ... and failed a lot" (FT23). The self-importance of bullying teachers is moreover illustrated in the next quotation: "I stormed into that room where they 
held their own meeting and I immediately instructed them to get out and go to the meeting I had arranged" (FT12). The bullies' desire to domineer others is additionally exemplified by a teacher who wrote: "I always have the last word" (FT15). The previous two, as well as the next quotation may however, also be seen as the personification of assertiveness: "I am quite outspoken and don't easily back down" (FHoD22). The writings of the bullies showed that some of them are proud of the fact that they have the upper hand: "From that day on she [the principal who she bullies] respects me ... I always [have] the last word and she feels frightened" (FT15) and "I felt superior to the person who I bullied ... my confidence skyrocketed" (MT2). Bullies in the workplace may thus be characterised as arrogant, insensitive, controlling, assertive and overconfident narcissistic individuals. This characterisation corroborates De Wet's (2010:1453) finding that bullies are articulate and systematic individuals who know how to play "the power game". Braithwaite et al. (2008) also believe that expressions of pride that take a narcissistic form can be associated with social dominance.

\title{
5.2 The nature of WPB
}

Since the commencement of research on WPB by Leymann (1996), as many as 43 different acts have been identified as WPB (Agervold, 2007). The teachers who took part in this study acknowledged that they were guilty of a wide variety of negative acts, ranging from verbal abuse ("just the usual jokes") (FT32), provocation ("sometimes I make them angry") (FHoD22), threatening behaviour ("I told her I will embarrass her in front of the learners") (FT18) to physical violence. Whereas one participant contemplated physical violence, another physically attacked her victim ("I kicked her") (FT21). Bullying teachers abused their powers within professional (ordered a meeting to disband) and private contexts (forcing victims to do personal tasks). Participants furthermore admitted harming their victims' professional status by humiliating them in front of pupils ("I make silly talk about my colleagues in front of the students") (FT25) and obstructing promotion ("he was interested in the principal-ship and I was a member of the election panel. I didn't allow him to get the post") (FHoD22). Bullying participants also conceded that they routinely ignored requests from colleagues. Teachers thus acknowledged that they verbally, emotionally and physically abused their colleagues. They admitted abusing their colleagues in front of pupils and colleagues, thus damaging their professional status. These types of negative acts have previously been identified by researchers (Agervold, 2007; Einarsen, 1999).

Whereas some researchers highlight intentionality as a core characteristic of WPB (cf. Agervold, 2007), a comment by a young female supports a widely held supposition by bullies (De Cuyper et al., 2009; Glasø et al., 2009), that they unintentionally committed acts of bullying:

\begin{abstract}
While reading these questions [referring to items in the questionnaire], I realise that some teachers might feel bullied by me. I can assure you that this is not my intention! I am quite outspoken and don't easily back down. I like to joke around and lighten the atmosphere. I can see that these could be observed as bullying and I will be more sensitive in future (FT19).
\end{abstract}

The following exposition (5.3) does not support the view of the above quoted teacher that bullies unintentionally harm their victims. It seems as if some of the participants were fully aware of the fact that they were committing WPB, since they justified their actions.

\subsection{Reasons for WPB in schools}

Most of the self-identified bullies (65.6\%) rationalised their negative behaviour. They went to great lengths to explain why they thought it necessary to strike out against antagonistic and other - seemingly innocent - colleagues. The participants retaliated against those who insinuated that they were incompetent, for example (e.g. "my colleague asked what kind of education I have for not being able to spell correctly" (FT12) and "she said I am useless" (FT16)), humiliated them in public ("I have bullied the principal because she always comes to my class to shout me") (FT32) and spread rumours about them ("that lady was telling lies about at me" (FT29) and "Someone misrepresented me as a bad person" (FT26)). Whereas all of the above-cited participants retaliated against alleged offenders, some of them transferred their retribution to third parties, as illustrated by the next two examples: A female teacher wrote that she was relentlessly bullied by one of her supervisors: "Now I also do that to my subordinates because I was treated like this" (FT5). An inexperienced participant who was told by colleagues that she was "useless ... end up having a lot of anger with colleagues at work ... I nearly hit one or two of my colleagues because of frustration I have" (FT16). Four participants acknowledged that they victimise colleagues of whom they are jealous. One of them wrote that she tries to humiliate teachers "who are the beloved of the principal" (FT18). Through the rationalisation of their own negative behaviour the bullying participants 
'normalise' their own behaviour (cf. Braithwaite et al., 2008; Jenkins et al., 2012). Glasø et al.'s (2009:1318) finding that bullies often act aggressively if their 'egotism' is threatened holds true for the current study. The assumption that perpetrators engage in bullying behaviour as a coping strategy in defending themselves against further acts of bullying is also supported by previous research (Hauge et al., 2009; Jenkins et al. 2012).

Three of the participants wrote that they bullied those whom they perceive to be incompetent. Whereas a HoD (M22) wrote that he "sometimes react verbally towards those who seem incompetent and make stupid mistakes", a teacher noted that he "attacked [his] colleague for not taking responsibility for invigilating [his] paper" (MT6). The suggestion of participants that they acted negatively towards colleagues because they were frustrated by colleagues' ineptness aligns with Baillien et al.'s (2008) and Bloch's (2012) argument that bullying is often initiated by bullies' inefficient coping with frustrations due to the (ineffectual) behaviour of the victim. From the perspective of alleged perpetrators, Jenkins et al. (2012) also found that poor performance was a frequent issue in WPB. Attempts at managing poor performance contributed to a number of complaints of bullying against the managers who took part in Jenkins et al.'s (2012) study. What managers often see as 'normal managerial duties' may be perceived as bullying by victims (Jenkins et al., 2012).

Being exposed to unequal work distribution, unmanageable workloads, cleaning up after incompetent colleagues, teaching subjects outside one's field of expertise is common experience in schools today, without this necessarily being related to bullying. Increased demands and target setting in a volatile South African education milieu, characterised by vast inequalities, pupil misbehavior, teachers' strikes and poor performance by teachers and pupils alike (Bloch, 2009) may result in bullying and firm/assertive management colliding and collapsing into one another.

Hauge et al.'s (2007) study rejects a finding of our study, namely that some employees become bullies because of frustration and uncontrollable events (e.g. incompetent, 'stupid' or lazy colleagues). According to Hauge et al. (2007) the reasons for WPB should rather be found in the bullies' disposition or lack of social competence. They base their assumption on the relatively low levels of job stressors reported by bullies who took part in their study. In accordance with the SDT, the self-reported bullies who took part in this study believed that the individuals who they victimised deserved to be treated unfairly. SDT suggests that the bullies' desire for the superior in-group to dominate those who are perceived to be inferior serves as an impetus and justification for their negative behaviour. Bullying is seen as a way of exercising control over incompetent, stupid and lazy colleagues. Aggressive strategies (e.g. yelling at colleagues) were used by the perpetrators to gain and maintain dominance, for example "I always [have] the last word" (FT15), "I felt superior" (MT2) and "my confidence sky-rocketed" (MT2).

Personal, health and lifestyle problems were also cited as reasons why the perpetrators targeted their colleagues. Whereas one wrote "I am not happy in my family" (FT32), two others noted that they are suffering from depression. A male teacher acknowledged that he is "using too much alcohol and smoking too much to increase my confidence" (MT6). This aligns with Einarsen et al.'s (2011) model, namely that WPB is characterised by multi-causality that involves not only organisational, but also personal factors.

Most of the self-identified bullies rationalised their negative behaviour and acknowledged that they intentionally used WPB to establish and maintain a superior-inferior relationship between them and their victims. Yet, there were five (15.6\%) self-identified bullies who reflected on their behaviour and acknowledged that their behaviour may have been wrong. A female teacher who verbally abused her victim conceded that she felt guilty. Conversely, a female teacher who stormed into a meeting wrote "I started feeling sorry and felt I could have handled the situation differently" (FT12), another a female bully said she apologised to her victim, because she realised her conduct was not "proper" (FT5). The critical self-reflection of the above-cited participants stands in contrast to Jenkins et al.'s (2012: 495) finding, namely that bullying managers often have "a very poor understanding of how inappropriate [their] behaviour was".

In accord with Einarsen et al.'s (2011) theoretical model, this study circuitously alluded to the interplay between organisational (e.g. weak leadership by principals who were guilty of favouritism, unwilling/unable to interfere in incidents of WPB and/or abused their official power; ineffective management control over the invigilating duties of members of staff and a lack of support for ineffectual/inexperienced colleagues) and individuals (e.g. a vindictive participant retaliated in kind because she was called "useless" (FT16), as well as self-righteous individuals who believe that they have the right to dominate others). These appear to be the elements which perpetuate WPB. Schools that lack positive, supportive leadership and a culture of respect allow domineering individuals to continue and even intensify their bullying behaviour. Note should also be taken of findings by international researchers (Baillien et al., 2008; Samnani \& Singh, 2012) that work-related characteristics such as high job insecurity, high strain jobs, low autonomy and a high workload often form the basis for frustrations and conflict, consequently leading to bullying. The latter is typical of the South African education dispensation. South African teachers are confronted by pupil misbehaviour, high teacher-pupil ratios and an everchanging curriculum (Van Tonder \& Williams, 2009). 
Teachers who took part in this study did not allude to the importance of the impact of socio-cultural, economic and legal elements on WPB. Although little is known about the influence society can have on WPB (Branch et al., 2013), the participants' rationalisation of their negative actions should be evaluated against societal elements, such as culture, the legal context and socio-economic factors. Burton (2001:24) found that South Africans "are more stressed than any other society in the workplace" because of continual and rapid change, economic uncertainty, unrealised expectations and a general feeling of disempowerment. The situation is especially volatile in schools where teachers are often confronted by racism, violence, gangsterism and children and colleagues infected and affected by HIVIAIDS, teacher strikes, lack of infrastructure, extreme poverty and the disintegration of social and family support structures (SAHRC, 2006).

\section{Limitations of the Study}

The results of this study should be considered in the light of its limitations. This is not a representative sample. All the respondents were teachers who were in the process of upgrading their qualifications. This implies that all the respondents - at the time of completing the questionnaires - did not comply with the National Policy Framework for Teacher Education and Development in South Africa which specifies that all teachers must have a degree (Cosser, Kraak \& Winnaar, 2011). Although this does not interfere with the aims of our study, the results cannot be generalised. The small sample size is an important limitation, even though Moreno-Jiménez et al. (2008) indicate that a low response rate is normal in research on WPB, given the sensitivity of the questions asked. A mere 3.2\% of these participants identified themselves as perpetrators of WPB. It may also be probable that the self-labelled perpetrators of WPB tried to portray themselves in a favourable light (Jenkins et al., 2012). Matthiesen and Einarsen (2007) however, believe that survey data may be valid to the extent that the participants answered the questions in an honest way and in accordance with their inner, subjective experiences.

\section{Conclusion}

Drawing upon Einarsen et al.'s model (2011) and SDT, this study aimed to shed light on the perpetrators of WPB in South African schools. Statistics show that teachers, rather than supervisors, are responsible for WPB. The self-identified bullies inadvertently characterised themselves as arrogant, insensitive, controlling, overconfident and narcissistic individuals. They were however, also portrayed as professionals with superior work ethics; they consequently lashed out in frustration against those who could not live up to their high standards. Drawing on dominant discourses the self-identified bullies bullied their incompetent, 'stupid', lazy, unprofessional and unprincipled colleagues. The self-identified bullies' negative behaviour is rationalised as a way to safeguard them against 'stupidity' and abuse. Personal, health and lifestyle problems were also identified as reasons for the bullies' negative behaviour. The bullies' encompassing desire to be part of the superior in-group lies at the heart of their negative behaviour. The abuse of power will however not be possible without overt and covert consent of the school as organisation and society as a whole. Findings from this study thus feeds into the discourse that the highly competitive capitalist economy, which characterise most workplaces worldwide, promotes the bullying of the weak by the strong.

Only 3.2\% of the teachers who took part in our study conceded that they bully their colleagues. Lack of critical self -reflection among bullies, and reluctance to concede being guilty of committing WPB is not uncommon in WPB research. There is a tendency to respond to questions in a socially desirable manner (cf. 5.1). Our negative characterisation and even monsterisation of those who were honest enough to admit being bullies may not have been fair. This study has shown that bullying is rife among teachers (cf. 5.1). Findings from this study do not exculpate others in the study who did not admit to bullying. There is a need for in-depth, qualitative research involving self-identified, as well as colleagueidentified bullies.

WPB may have a negative effect on teacher effectiveness in a country whose education system is often cited as a national disaster (Bloch, 2009). Without dedicated and motivated teachers who feel physically and emotionally secure in their work environment, they will not be able to play a pivotal role in addressing the demands of an ever-changing education landscape. There is thus a pressing need to address WPB in South African schools. Policies to address WPB should however, not be limited to teachers, but should embrace all employees in South Africa. South African labour legislation lacks an explicit definition of workplace bullying (Le Roux, Rycroft \& Orleyn, 2010). These policies need to be institutionalised and procedures put in place for reporting and investigating incidents of WPB. The training of all employees should be implemented for the purpose of recognising, dealing with and preventing WPB.

The current study contributes to the limited body of South African and international knowledge on WPB from the perspective of the bullies (cf. 3). We agree with Samnani and Singh's (2012:582) assertion that research on perpetrators 
"remains work-in-progress" and therefore highlight the need for more research on the topic from the perspective of selflabelled bullies.

\section{References}

Agervold, M. (2007). Bullying at work: a discussion of definitions and prevalence, based on an empirical study. Scandinavian Journal of Psychology, 48, 161-172.

Baillien, E., Neyens, I., De Witte, H., \& De Cuyper, N. (2008). A qualitative study on the development of workplace bullying: Towards a three-way model. Journal of Communication \& Applied Social Psychology, 19, 1-16.

Blasé, J., \& Blasé, J. (2002). The dark side of leadership: teacher perspectives of principal mistreatment. Educational Administration Quarterly, 38(5), 671-727.

Blasé, J., Blasé, J. \& Du, F. (2008). The mistreated teacher: a national study. Journal of Educational Administration, 46(3), $263-301$.

Bloch, C. (2012). How do perpetrators experience bullying at the workplace? International Journal of Work Organisation and Emotion, $5(2), 159-177$.

Bloch, G. (2009). The toxic mix: What's wrong with South Africa's schools and how to fix it. Cape Town: Tafelberg.

Braithwaite, V., Ahmed, E., \& Braithwaite, J. (2008). Workplace bullying and victimization: the influence of organizational context, shame and pride. International Journal of Organisational Behaviour, 13(2), 71-94.

Branch, S. (2008). You say tomatoe and I say tomato: can we differentiate between workplace bullying and other counterproductive behaviours? International Journal of Organisational Behaviour, 13(2), 4-17.

Branch, S., Ramsay, S., \& Barker, M. (2013). Workplace bullying, mobbing and general harassment: a review. International Journal of Management Review, 15(3), 280-299.

Burton, L. (2001). Violence at work in South Africa. People Dynamics, March, 24-25.

Cemaloglu, N. (2007). The exposure of primary school teachers to bullying: an analysis of various variables. Social Behavior and Personality, 35(6), 789-802.

Cosser, M., Kraak, A., \& Winnaar, L. (2011). Further Education and Training (FET) Colleges at a glance in 2010. Pretoria: HSRC.

Cunniff, L., \& Mostert, K. (2012). Prevalence of workplace bullying of South African employees. South African Journal of Human Resource Management, 10(1), 1-15.

De Cuyper, N., Baillien, E., \& De Witte, H. (2009). Job insecurity, perceived employability and targets' and perpetrators' experiences of workplace bullying. Work \& Stress, 23(3), 206-224.

De Wet, C. (2010). The reasons for and the impact of principal-on-educator bullying on the victims' private and professional lives. Teaching and Teacher Education, 26(7), 1450-1459.

Einarsen, S. (1999). The nature and causes of bullying at work. International Journal of Manpower, 20(1/2), 16-27.

Einarsen, S., Hoel, H., Zapf, D., \& Cooper, C.L. (2011). The concept of bullying and harassment at work: the European tradition. In S. Einarsen, H. Hoel, D. Zapf \& C.L. Cooper (Eds.), Bullying and harassment in the workplace (pp. 3-40). Boca Raton, CL: Taylor \& Francis.

Glasø, L., Nielsen, M.B., \& Einarsen, S. (2009). Interpersonal problems among perpetrators and targets of workplace bullying. Journal of Applied Social Psychology, 39(6), 1316-1333.

Hauge, L.J., Skogstad, A., \& Einarsen, S. (2007). Relationship between stressful work environments and bullying: results from a large representative study. Work \& Stress, 21(3), 220-242.

Hauge, L.J., Skogstad, A., \& Einarsen, S. (2009). Individual and situational predictors of workplace bullying: Why do perpetrators engage in the bullying of others? Work \& Stress, 23(4), 349-358.

Henning, E., Van Rensburg, W., \& Smit, B. (2011). Finding your way in qualitative research. Pretoria: Van Schaik.

Jenkins, M.F., Zapf, D., Winefield, H., \& Sarris, A. (2012). Bullying allegations from the accused bully's perspective. British Journal of Management, 23(4), 489-501.

Kirsten, G.J.C., Viljoen, C.T., \& Rossouw, J.P. (2005). Bullying by educational managers with narcissistic personality disorder: a health protection and psycho-legal issue? Paper presented at the meeting of the South African Education Law and Policy Association, Bloemfontein, South Africa.

Le Roux, R., Rycroft, A., \& Orleyn, T. (2010). Harassment in the workplace: law, policies and processes. Durban: LexisNexis.

Leymann, H. (1996). The content and development of mobbing at work. European Journal of Work and Organizational Psychology 5(2), 165-184.

Lutgen-Sandvik, P. \& McDermott, V. (2011). Making sense of supervisory bullying: perceived powerlessness, empowered possibilities. Southern Communication Journal, 76(4), 342-368.

Marais-Steinman, S. (2003). Workplace violence in the health sector. Country case study: South Africa. [Online] Available: www.who.int/violence.../violence/ .../en/ WVcountrystudysouthafrica.pdf (June 15, 2011).

Matthiesen, S.B. \& Einarsen, S. (2007). Perpetrators and targets of bullying at work: role stress and individual differences. Violence and Victims, 22(6), 735-753.

Momberg, M.A. (2011). The prevalence and consequences of workplace bullying in South Africa. Master's dissertation, Nelson Mandela Metropolitan University, Port Elizabeth, South Africa.

Moreno-Jiménez, B., Muňoz, A.R., Salin, D., \& Benadero, M. E. M. (2008). Workplace bullying in Southern Europe: prevalence, forms and risk groups in a Spanish sample. International Journal of Organisational Behaviour, 13(2), 95-109. 
Parkin, I.S., Fishbein, H.D., \& Richey, P.N. (2006). The influence of personality on workplace bullying and discrimination, Journal of Applied Social Psychology, 36, 2554-2577.

Parzefall, M., \& Salin, D.M. (2010). Perceptions of and reactions to workplace bullying: A social exchange perspective. Human Relations, 63(6), 761-780.

Pratto, F., \& Stewart, A.L. (2012). Social Dominance Theory. The Encyclopaedia of Peace Psychology. First Edition. Blackwell Publishing Ltd.

SAHRC (South African Human Rights Commission). (2006). Report of the public hearing on the basic right to basic education. Pretoria: SAHRC.

Samnani, A. (2013). Embracing new directions in workplace bullying: A paradigmatic approach. Journal of Management Inquiry, 22(1), 26-36.

Samnani, A., \& Singh, P. (2012). 20 years of workplace bullying research: A review of the antecedents and consequences of bullying in the workplace. Aggression and Violent Behaviour, 17, 581-589.

Shallcross, L. Sheehan, M., \& Ramsay, S. (2008).Workplace mobbing: experiences in the public sector. International Journal of Organisational Behaviour, 13(2), 56-70.

Shao, P., Resick, C.J., \& Hargis, M.B. (2011). Helping and harming others in the workplace: The role of personal values and abusive supervision. Human Relations, 64(8), 1051-1078.

Van den Broeck, A., Baillien, E., \& De Witte, H. (2011). Workplace bullying: a perspective from the Job Demands-Resource model. South African Journal of Industrial Psychology, 37(2), 1-15.

Van Tonder, C.L., \& Williams, C. (2009). Exploring the origins of burnout among secondary educators. South African Journal of Industrial Psychology, 35(1), 1-15.

Yildirim, D., Yildirim, A., \& Timucin, A. (2007). Mobbing behaviours encountered by nurse teaching staff. Nursing Ethics, 14(4), 447-463.

Zapf, D. (1999). Organisational, work group related and personal causes of mobbing/bullying at work. International Journal of Manpower, 20(1/2), 70-85.

Zapf, D., \& Einarsen, S. 2003. Individual antecedents of bullying. In S. Einarsen, H. Hoel, D. Zapf \& C.L. Cooper (Eds.), Bullying and emotional abuse in the workplace (pp. 165-184). London: Taylor \& Francis. 